\title{
A IMPORTÂNCIA DA CONTROLADORIA PARA A GESTÃO
}

\author{
Beatriz Pereira Ferreira ${ }^{5}$ \\ Cassiana Soraia Oliveira Dornelas ${ }^{6}$ \\ Janiny Ferreira dos Santos $^{7}$ \\ Joyce da Costa Marques ${ }^{8}$ \\ Altamiro Lacerda de Almeida Junior ${ }^{9}$
}

\section{RESUMO}

O objetivo desse estudo é demonstrar que a Controladoria é de suma importância para o auxilio na tomada de decisões e gestão nas organizações. Para constatação do estudo a metodologia adotada foi à pesquisa exploratória, e as fontes de dados e informação foram obtidas através de pesquisa bibliográfica. Os resultados indicam que a Controladoria deve estar atrelada a gestão para garantir eficácia empresarial e assegurar a existência da empresa no mercado. Foi concluído que a Controladoria é indispensável para que a gestão possa fluir de maneira mais assertiva.

Palavras-Chaves: Controladoria; Gestão; Controller;

\section{INTRODUÇÃO}

A Controladoria é um segmento de administração ou contabilidade e surgiu para suprir a necessidade das organizações de acompanhar de forma precisa o andamento de seus processos, isso ocorre através do comando do profissional chamado Controller. É comum nos depararmos com a instabilidade de muitas organizações, outras nem mesmo conseguem continuar suas atividades e se consolidar no mercado, isso ocorre, muitas das vezes não por uma situação financeira ruim, mas pela falta de planejamento e de uma boa gestão.

A proposta para esse ensaio é destacar o papel do Controller nas organizações. A pesquisa caracteriza-se como exploratória, para Gil (1999) estes tipo de pesquisas "são desenvolvidas com objetivo de proporcionar visão geral, de tipo aproximativo, acerca de determinado fato". Utilizou-se como técnica de pesquisa a pesquisa bibliográfica em materiais já publicados e que porporcionam melhor oportunidade de sistematização do conhecimento.

O estudo está organizado em: revisão da literatura onde apresenta-se o surgimento da controladoria; a perspectiva conceitual da controladoria; e o controller. Por fim, apresenta-se as considerações finais e as referências.

Espera-se que o conteúdo apresentado desperte o desejo dos profissionais das Ciências Contábeis por essa àrea de atuação.

\footnotetext{
${ }^{5}$ Bacharela em Administração - FIC/UNIS; Graduanda em Ciências Contábeis - FIC/UNIS

${ }^{6}$ Graduanda em Ciências Contábeis - FIC/UNIS

${ }^{7}$ Graduanda em Ciências Contábeis - FIC/UNIS

${ }^{8}$ Graduanda em Ciências Contábeis - FIC/UNIS

${ }^{9}$ Mestre em Administração - UFV; Especialista em Marketing e Negócios - UFJF; Bacharel em Administração - FIC/UNIS; Professor FIC/UNIS e UEMG.
} 


\section{REVISÃO DA LITERATURA}

\subsection{Surgimento da Controladoria}

A controladoria passa necessáriamente pelo processo de evolução da gestão. A gestão é um elemento das ciências humanas, que tem por objetivo gerenciar e administrar uma organização, procurando manter a sinergia entre todos os recursos envolvidos na dinamica organizacional.

"O processo de gestão deve garantir o cumprimento das metas, objetivos e missão da empresa, de maneira equilibrada e adaptável às mudanças. Ele deve ser: estruturado com base no processo decisório, contemplar o planejamento, execução e controle e ser suportado por sistemas de informações. Ele também se encontra nas fases de planejamento estratégico e operacional. A função da controladoria no processo de gestão é fornecer informações sobre o desempenho e resultados econômicos e monitorar o processo de elaboração do orçamento (PEREIRA, 2001 in: CATELLI, 2001 pag. 08).”

De acordo com Tung (1997), a controladoria surgiu para ampliar e disseminar o entendimento do processo de gestão, identificando a razão de ser de uma organização e quais fatores estão contribuindo ou não, para a eficiência e eficácia de suas operações, de forma que se assegure a continuidade do negócio pela geração contínua de resultados econômicos favoráveis.

Dentre os diversos ramos de atuação da Administração um deles vem obtendo um grande destaque nas últimas décadas, a Contabilidade Gerencial ou Controladoria, devido à sua importante e indispensável atuação nas empresas, pois, esta promove informações preciosas para o crescimento e o desenvolvimento empresarial. Atualmente com as duas grandes Revoluções Industriais e com a grande evolução tecnológica, a Contabilidade e a Administração evoluíram de forma a proporcionar ao profissional diversas áreas de atuação, sendo uma delas a Contabilidade Gerencial (ARAÚJO; ROCHA, 2007 pag. 02 ).

\subsection{Perspectiva conceitual da Controladoria}

Beuren (2002) relata em sua obra que é importante e necessário o envolvimento da área de controladoria no processo de gestão de uma empresa, para o autor, a controladoria tem por objetivo contribuir para a melhoria na tomada de decisões, assim como propor para o aperfeiçoamento dos instrumentos de gestão, seja na fase do planejamento, implementação ou controle. De acordo com Borinelli (p.105, 2006) a controladoria "é um conjunto de conhecimentos que se constituem em bases teóricas e conceituais de ordens operacional, econômica, financeira e patrimonial". Para alcançar tais propósitos é comum utilizar modelos e aplicações de pesquisa operacional, estatística e outros recursos que possam auxiliar nos sistemas de informação (BEUREN, 2002).

Almeida et al. (2001) afirmam que a controladoria reúne dois vérticies que se somam para melhor compreensão do todo na organização: 
A controladoria não pode ser vista como um método voltado ao como fazer. Para uma correta compreensão do todo, devemos cindi-la em dois vértices: o primeiro como ramo do conhecimento responsável pelo estabelecimento de toda a base conceitual, e o segundo como órgão administrativo respondendo pela disseminação do conhecimento, modelagem e implantação de sistemas de informação (ALMEIDA et al. P.344, 2001)

Com base nos estudos de CASTRO, Cristiano Alves (2018), o conceito de controladoria pode ser empregado para duas linhas distintas: a primeira como campo administrativo que desenvolve o controle e planejamento financeiro de uma organização, este tipo de controladoria está alicerçado em um sistema de informação gerencial; a segunda linha de atuação está relacionada com uma área de estudo onde se emprega conceitos e metodologias originários de outras ciências.

Para Filho (2015) entre os objetivos da controlodoria estão oferecer a organização um sistema de dados que auxiliem na formulação de informações, que poderão subsidiar os executivos na tomada de decisões. Para o autor, a controloadoria contribui para sobrevivência e eficácia organizacional, por meio dela é possívela otimização dos resultados.

Heckert e Willson (1963) comparam a controladoria com um navegador responsável por assessorar a embarcação até o destino final.

A controladoria não é responsável pelo comando do navio, função do primeiro executivo; ela é, contudo, simbolizada pelo navegador que deve cuidar dos mapas de navegação, devendo assessorar e informar o comandante a respeito da velocidade localização e trajeto percorrido pelo barco, alertando, ainda, sobre eventuais perigos, como recifes e desvios de rotas. Sua função é, portanto, assegurar que a embarcação alcance seu destino em segurança (HECKERT e WILLSON, p. 34, 1963).

Filho (2015), ainda contribui informando que a Controladoria deve monitorar, informar e influenciar a direção coorporativa assumindo um papel ativo e comprometendo-se com os resultados da empresa.

\subsection{O Controller}

De acordo com Beuren (2002) o controller é o profissional responsável pela área de controladoria, ele é o responsável pelo sistema de informações da empresa, entre suas atribuições está a de manter os gestores informados sobre os eventos do passado, a situação atual e os possíveis rumos da empresa.

Para Tung (1997), Controller é o executivo financeiro que detém as responsabilidades sobre os setores de contabilidade, orçamento, planejamento, controle de impostos, auditoria e outras atividades das empresas.

Kanitz (1976) menciona sobre várias atribuições de um Controller. Cabe ressaltar que, a sua função básica consiste em gerenciar, além de implantar os seguintes sistemas: informação, motivação, coordenação, avaliação, planejamento e acompanhamento.

Segundo Tung (1980), o controller é responsável pela coordenação e apoio à administração em suas funções de planejamento, controle e proteção dos interesses da empresa. E dentro destas funções, podem-se considerar algumas atribuições:

- Estabelecer, manter, coordenar, assessorar, consolidar, avaliar e informar o orçamento da empresa. 
- Estabelecer, manter e coordenar um sistema de controle e de relatórios gerenciais.

- Estabelecer e manter um sistema de auditoria interna operacional e contábil e coordenar os trabalhos de auditoria externa.

- Coordenar, avaliar e informar o desempenho da empresa e desvios em relação aos planos e metas, identificando e quantificando suas causas e efeitos.

-Elaborar relatórios econômico-financeiros para agentes externos. - Administrar encargos e impostos.

Oliveira, Perez Junior e Silva (2007) descrevem as atividades do controller como forma de prever os problemas, elaborar relatórios gerenciais e fornecer informações para o processo de tomada de decisão.

\section{CONSIDERAÇÕES FINAIS}

O objetivo do trabalho apresentado foi expor, de forma didática e metodológica com base em pesquisa acadêmica, o papel que desempenha o controller no cenário contábil.

Certo de que o foco de uma empresa é a rentabilidade, o meio que se usa para se obter tal objetivo se perde mediante a diversidade de variáveis encontradas para a execução com conhecimento hábil, fundamental para encarar esse mercado voraz presente atualmente.

Na necessidade de se obter um norte para esses lideres, evidenciam pesquisadores renomados como Heckert e Wilson (1963), fazendo analogia à controladoria e ao navegador, deixando clara a importância do conhecimento específico para interpretar e saber analisar, tomando assim, a decisão mais acertada para a situação. Assim, para o profissional Controller são necessários atributos como conhecimento em contabilidade, orçamento, planejamento, controle de impostos, auditoria e outras atividades das empresas, sendo indispensável para que a gestão possa fluir de maneira mais assertiva.

Com tudo, o papel do controller na organização é tão importante, e nos faz ver a necessidade de poder optar por essa função, é uma área ampla e bastante abrangente, faz ter uma visão total da empresa, tanto no planejamento estratégico, tático e o operacional, se tornando uma peça chave para ao sucesso da empresa.

\section{REFERÊNCIAS BIBLIOGRÁFICAS}

MARCONI, M. A.; LAKATOS, E. M. Fundamentos de metodologia científica. $6^{\text {a }}$ Ed.São Paulo:Atlas, 2007.

GIL, Antônio Carlos. Métodos e Técnicas de pesquisa social. $5^{\text {a }}$ Ed. São Paulo São Paulo:Atlas, 1999

SOUZA, Bruno C.; BORINELLI, Marcio L.Controladoria.Curitiba, PR: Editora IESD Brasil,2012.

TUNG, N. H. Controladoria financeira das empresas. 4 ed. São Paulo: Edições Universidade Empresa, 1997.

TUNG, N. H. Controladoria financeira das empresas. 4 ed. São Paulo: Edições 
Universidade Empresa, 1997.

KANITZ, Stephen C. Controladoria: Teoria e Estudo de Casos. São Paulo: Pioneira, 1976.

OLIVEIRA, Luís Martins de; PEREZ JUNIOR, José Hernandez/ SILVA, Carlos Alberto dosSantos. Controladoria Estratégica. 4ª Ed. São Paulo: Atlas, 2007.

FILHO, Valter Pereira Francisco. Planejamento e Controladoria Financeira. São Paulo: Pearson Education do Brasil, 2015. 


\title{
AUDITORIA: conceitos, características e especificidades
}

\author{
Beatriz Teza de Oliveira ${ }^{10}$ \\ Monik Fialho Barbosa ${ }^{11}$ \\ Miriã Medeiros Rosa ${ }^{12}$ \\ Antônio Felicio Batista Filho ${ }^{13}$ \\ Jaqueline Aparecida Bayonetta de Souza ${ }^{14}$
}

\section{RESUMO}

O trabalho possui como objetivo analisar os conceitos e especificidades da auditoria e sua importância nas organizações. A metodologia utilizada consiste na pesquisa bibliográfica e na revisão narrativa, não sendo empregados critérios explícitos ou sistemáticos na busca e na análise crítica da literatura. Foi possível conceituar a auditoria como um estudo de avaliação contábil, utilizando métodos eficazes de revisão das demonstrações financeiras, contábeis, de registros e operações. Seu principal objetivo é enquadrar a organização nas normas e legislações vigentes, testando a eficiência do controle patrimonial e expressando uma opinião embasada em análises sobre determinado dado. A auditoria externa é aquela realizada por auditores independentes, não possuindo vínculo com a empresa. A auditoria interna é realizada por profissionais da própria entidade, não necessitando ser da área contábil. Para o sucesso da auditoria, o auditor deve possuir um perfil qualificado para exercer suas atividades, interagindo com os demais funcionários, mantendo um vínculo profissional com a empresa e oferecendo suporte para a gestão da instituição.

Palavras-chave: Auditoria. Auditor. Ferramenta Contábil.

\section{INTRODUÇÃO}

Com a aplicação dos procedimentos de auditoria, Santos (2016) explica que o auditor busca avaliar se os critérios estabelecidos estão sendo ou não atendidos. Ou seja, constitui fatos resultantes dos programas de auditoria que podem remeter a deficiências

\footnotetext{
${ }^{10}$ Graduanda em Ciências Contábeis - FIC/UNIS

${ }^{11}$ Graduanda em Ciências Contábeis - FIC/UNIS

12 Graduanda em Ciências Contábeis - FIC/UNIS

${ }^{13}$ Graduando em Ciências Contábeis - FIC/UNIS

${ }^{14}$ Especialista em Contabilidade Tributária - Faculdade Machado Sobrinho; Bacharel em Ciências Contábeis - Faculdade Sudamérica; Professor FIC/UNIS.
} 
encontradas nas organizações auditadas. Tanto a auditoria interna quanto a externa colaboram na gestão das entidades, entendendo que a complexidade operacional e demandas por controle do patrimônio necessitam do acompanhamento feito por parte dos gestores, controladores ou fornecedores de capital.

Dessa forma, a presente pesquisa se justifica pela auditoria estar cada vez mais presente nas organizações, constituindo uma ferramenta que favorece o controle de

qualquer entidade. É, portanto, necessário o seu entendimento por parte dos gestores e de profissionais como administradores e contadores, proporcionando melhor atuação no mercado de trabalho e garantindo a transparência e conformidade no funcionamento das organizações.

O trabalho possui como objetivo geral: analisar os conceitos e especificidades da auditoria e sua importância nas organizações.

Como objetivos específicos, possui: entender os diferentes tipos de auditoria e analisar o papel do auditor.

A metodologia utilizada consiste na pesquisa bibliográfica e na revisão narrativa, não sendo empregados critérios explícitos ou sistemáticos na busca e na análise crítica da literatura. Sua realização se dará através do estudo de textos, livros e artigos científicos, disponíveis no formato físico e também na internet, encontrados em bases de dados como SciELO e Google Acadêmico. Os critérios de inclusão utilizados abrangem trabalhos completos e disponíveis gratuitamente, que possuam ligação direta com a temática estudada, tendo como descritores: auditoria, auditor, ferramenta contábil.

\section{DESENVOLVIMENTO}

Santos (2016) define a auditoria como o estudo contábil de avaliação de métodos referentes à empresa, bem como uma forma de revisão das demonstrações financeiras, contábeis, registros e operações. Possui como objetivo enquadrar a organização nas normas e legislações vigentes. A auditoria é, portanto, uma especialização contábil que busca testar a eficiência do controle patrimonial, expressando uma opinião sobre determinado dado. Buscando um maior destaque no mercado, muitas empresas vêm investindo em novas ferramentas de gestão, incluindo a auditoria, com o intuito de auxiliar na tomada de decisão.

Para Santos (2016), no Brasil, a evolução da auditoria ocorreu devido ao desenvolvimento econômico, gerando crescimento na administração dos negócios e das 
práticas financeiras, assim como a busca pelo retorno do capital aplicado de modo lícito, juntamente com o retorno do investimento. Entende-se que é no controle interno que o auditor inicia o seu trabalho de auditoria, determinando a quantidade de exames que serão realizados e, se a organização possui bons controles internos, isso poderá facilitar e reduzir o trabalho do auditor.

Já Araújo (2008) define a auditoria como uma especialização da contabilidade, criada para ser utilizada como uma ferramenta de confirmação da própria contabilidade. Ela vem evoluindo junto com a contabilidade, em decorrência das mudanças econômicas que ocorreram ao longo do tempo. Com isso, surgem sócios e administradores que precisam de informações concretas sobre o capital investido, exigindo um profissional independente que possui capacidade técnica e não tenha vínculo direto ou indireto com a instituição, para analisar as demonstrações contábeis. Esse profissional, denominado auditor-contábil, deve analisar essas demonstrações a partir de levantamentos, prestando as devidas informações quanto ao que está ocorrendo com o patrimônio da empresa.

Conforme a Instrução Normativa $n^{\circ}$ 01/2001, Moreira e Baran (2018) apontam que a auditoria contábil abrange o exame de registros e documentos pertinentes ao controle do patrimônio de uma entidade, buscando obter elementos comprobatórios para que se possa opinar se os mesmos estão de acordo com os princípios contábeis, e se as demonstrações contábeis refletem a situação da empresa. A auditoria contábil é, portanto, a certificação dos elementos da contabilidade com o exercício da sociedade empresarial, buscando assegurar a credibilidade das informações das peças contábeis e a integridade do patrimônio, objetivando minimizar os riscos operacionais, fiscais, societários, ambientais, trabalhistas, previdenciários através de técnicas específicas.

De acordo com Pinheiro e Cunha (2003), em decorrência da evolução das fraudes, tanto no aspecto quantitativo quanto no aspecto qualitativo, as mesmas atingem empresas públicas e privadas, principalmente em países desenvolvidos e emergentes, ocasionando grandes perdas nos patrimônios dessas organizações. Quando a empresa exerce atividades ilícitas, possibilita o surgimento de um ambiente propício para a ocorrência de fraudes que, dependendo da intensidade, poderá ocasionar uma descontinuidade operacional da entidade. Com isso, a auditoria deverá aplicar um exame sistemático dos registros, demonstrações e demais elementos de consideração contábil, buscando apresentar opiniões, conclusões, críticas e orientações sobre situações e fenômenos patrimoniais, público ou privado. 
Sobre o processo de auditoria, Moreira e Baran (2018) apontam que constituem etapas que buscam examinar a regularidade da gestão administrativa, auxiliando nos aperfeiçoamentos dos processos e controles internos da empresa, onde o auditor planeja o seu trabalho adequadamente, conforme disposto na Figura 01.

Figura 01: Processos da auditoria

Planejamento e

Levantamento

do processo
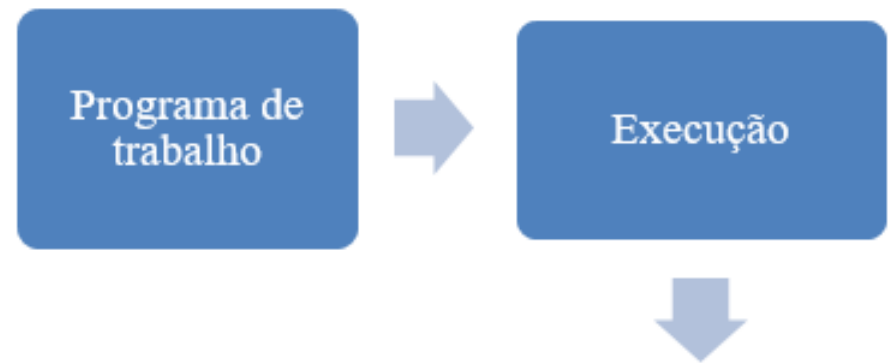

Monitoramento

das

Recomendações
Relatório e

Conclusão

Fonte: Moreira e Baran (2018)

Para Moreira e Baran (2018), no Planejamento e Levantamento do Processo, o auditor realiza a documentação do seu planejamento, preparando o programa de trabalho por escrito e realizando a análise dos riscos. É a fase onde se identifica os problemas da entidade, define os exames adequados para executar o trabalho em tempo hábil, garante a uniformidade dos levantamentos, divide as tarefas buscando evitar sobrecarga de trabalho. O Programa de Trabalho é a fase final do planejamento, onde são definidos os meios mais econômicos e eficientes para que os objetivos da auditoria sejam atingidos. $\mathrm{Na}$ fase de Execução ocorre uma reunião de abertura dos trabalhos com o auditado, o estudo e avaliação dos controles internos, a aplicação dos programas de auditoria e o registro em papeis de trabalho. O Relatório e Conclusão é o documento que apresenta a conclusão do trabalho de auditoria expondo erros, fraudes ou deficiências que foram verificadas no decorrer da auditoria, contendo uma linguagem clara e nítida, permitindo o entendimento das informações. Já o Monitoramento das Recomendações consiste no acompanhamento dos processos com relação às orientações recebidas, assegurando que os processos sejam realizados de forma correta, buscando a prevenção de irregularidades. 
Segundo Attie (2007), com o desenvolvimento de leis e normas, para o setor de auditoria, o processo de análise dessas leis foi controlado com maior rigidez pelos órgãos competentes, criados exclusivamente para isso. A responsabilidade legal da auditoria das operações somente pode ser analisada por meio de provas seletivas, cabendo ao auditor definir a quantidade de operações que devem ser analisadas, averiguando a segurança dessas informações e investigando documentos válidos, buscando no controle interno e na administração, subsídios que ofereçam uma garantia para as informações avaliadas.

Para Moreira e Baran (2018), a auditoria pode ser externa e interna. A auditoria externa é realizada por auditores independentes, que não possuem vínculo com a empresa e tem, como objetivo principal, examinar documentações e demonstrações contábeis para emitir um parecer sobre a situação da empresa, ou seja, busca pela veracidade dos dados, averiguando o nível de segurança dos controles internos da organização. Já a auditoria interna, é realizada por profissionais da própria empresa, não precisando ser, necessariamente, da área contábil.

Já Franco e Marra (2001) classificam a auditoria em auditoria financeira, auditoria de cumprimento e auditoria operacional. A auditoria financeira busca apresentar as demonstrações financeiras da entidade como um todo, tendo como objetivo fazer com que o auditor expresse uma opinião sobre as demonstrações financeiras e se estão de acordo com os princípios da contabilidade. A auditoria de cumprimento abrange a revisão, comprovação e avaliação dos controles e procedimentos operacionais de uma entidade. A auditoria operacional apresenta um exame mais detalhado da administração, dos recursos técnicos e do desempenho de uma organização, buscando medir o grau em que as atividades da entidade estão alcançando os seus objetivos.

A importância da auditoria é explicada por Flozino e Silvério (2014), devido ao crescimento acelerado das atividades econômicas das empresas e das dificuldades que os gestores encontram em controlar de forma individual cada seguimento da organização, seja por falta de tempo, preparo ou suporte para a concretização de seus objetivos. Com isso, é possível perceber a importância da auditoria nas organizações, visto que possui ferramentas necessárias para o controle administrativo, permitindo a identificação e resolução dos problemas. Além disso, irá auxiliar os gestores na tomada de decisões, já que quando aplicada, possibilitará uma maior confiabilidade nas informações contidas no balanço contábil.

Flozino e Silvério (2014) apontam que os órgãos relacionados aos auditores compreendem a Comissão de Valores Mobiliários, sendo um órgão fiscalizador do 
mercado de capitais no Brasil, que busca estabelecer regras para auditores independentes e normas relacionadas à forma de apresentação e divulgação das informações contábeis ao mercado; o Instituto Brasileiro de Contadores, que é uma pessoa jurídica de direito privado sem fins lucrativos, e que representa os interesses dos auditores independentes e atua como agente participante da regulação da atividade de contabilidade e auditoria independente em convergência com as demais entidades reguladoras; os Conselhos Regionais de Contabilidade, que representam entidades de classe dos contadores, registrando e fiscalizando o exercício da profissão e o Instituto dos Auditores Internos do Brasil, que é uma entidade civil de direito privado e sem fins lucrativos, que busca promover o desenvolvimento da auditoria interna através de ideias, reuniões, conferências e publicações.

O auditor, segundo Rodrigues (2011), era visto, antigamente, como aquele que apenas apontava os erros, visto com uma imagem autoritária perante os auditados. Porém, atualmente, não é visto apenas como um fiscalizador, mas um auxiliador, que possui um importante papel dentro da empresa, possuindo um perfil qualificado para exercer suas funções e que sabe interagir com os demais empregados, mantendo um vínculo profissional e independente, sendo um importante suporte para a gestão da empresa.

\section{CONCLUSÃO}

Ao término da presente pesquisa, foi possível conceituar a auditoria como um estudo de avaliação contábil, utilizando métodos eficazes de revisão das demonstrações financeiras, contábeis, de registros e operações. Seu principal objetivo é enquadrar a organização nas normas e legislações vigentes, testando a eficiência do controle patrimonial e expressando uma opinião embasada em análises sobre determinado dado. Com isso e investindo em novas ferramentas de gestão, uma empresa poderá se destacar no mercado.

A auditoria externa é aquela realizada por auditores independentes, não possuindo vínculo com a empresa e busca examinar documentações e demonstrações contábeis para a emissão de um parecer sobre a situação da organização. A auditoria interna é realizada por profissionais da própria entidade, não necessitando ser da área contábil.

O curso de Ciências Contábeis é bastante interdisciplinar, com um currículo que abrange as disciplinas contabilidade, custos, tributária e direito. O profissional que optar pela área de auditoria terá como necessidade a atualização constante decorrente das 
mudanças nas normas, responsabilidade técnica e conhecimentos específicos. Dentro das organizações que prestam o serviço de auditoria independente, esse profissional poderá evoluir na carreira, trabalhando em equipes e podendo até chegar a ser sócio depois de algum tempo desempenhando sua função. Poderá ainda ter o seu próprio escritório de auditoria independente. Além disso, a demanda por esses profissionais é grande, e cada vez mais empresas buscam por seus serviços, entendendo que a auditoria constitui um investimento e não um custo às organizações.

O crescimento acelerado das atividades econômicas das empresas aponta para dificuldades de se controlar individualmente cada seguimento das mesmas. Dessa forma, a auditoria apresenta ferramentas permitindo a identificação e resolução de problemas, proporcionando ainda uma maior confiabilidade nas informações contidas no balanço contábil. Para o sucesso da auditoria, o auditor deve possuir um perfil qualificado para exercer suas atividades, interagindo com os demais funcionários, mantendo um vínculo profissional com a empresa e oferecendo suporte para a gestão da instituição.

\section{REFERÊNCIAS}

ARAÚJO, Inaldo. Introdução à auditoria operacional. Rio de Janeiro: Editora FGV, 2008.

ATTIE, William. Auditoria Interna. São Paulo: Atlas, 2007.

FLOZINO, Angélica; SILVÉRIO, Fábio. Auditoria interna e a importância para micro e pequenas empresas. Revista Interatividade, v. 02, n. 02, 2012.

FRANCO, H; MARRA, E. Auditoria contábil. São Paulo: Atlas, 2001.

MOREIRA, Aleziandra; BARAN, Kelly. A importância da auditoria interna para as organizações. Revista Científica Multidisciplinar Núcleo do Conhecimento, v. 05, n. 02, 2018.

PINHEIRO, Geraldo; CUNHA, Luís. A importância da auditoria na detecção de fraudes. Contabilidade Vista e Revista, v. 14, n. 01, 2003.

RODRIGUES, Ernesto. Auditoria Contábil. Monografia. Universidade Federal de Santa Catarina. Departamento de Ciências Contábil, 2011.

SANTOS, Silas. Auditoria interna de gestão. Artigo científico. Faculdade São Francisco de Barreiras. Curso de Ciências Contábeis. Barreiras, 2016. 


\title{
CONTABILIDADE: AS PRIMEIRAS PERCEPÇÕES RELACIONADAS À CRISE DE COVID-19
}

\author{
Beatriz Pereira Ferreira Alves \\ Altamiro Lacerda de Almeida Junior \\ Jaqueline Aparecida Bayonetta de Souza \\ Silene Aparecida Zampier Alves \\ Patrícia Margato da Silva Rodrigues
}

\section{RESUMO}

Este estudo discorre sobre as primeiras percepções relacionadas à crise de COVID-19 no âmbito da contabilidade. Tal abordagem é devida ao fato de que houve muitas mudanças e atualização na legislação brasileira para incorporação de medidas tributarias e de manutenção de empregos a fim de evitar demissões em massa e ajudar as empresas a se manterem nesse período de crise, o que acarreta uma fase de grande adaptação e um aumento de demanda de trabalho para os empresários e especificamente os escritórios de contabilidade. A finalidade deste estudo é demonstrar como tem sido as primeiras medidas de enfrentamento dos contadores e contabilistas diante de tal cenário. Este estudo possui uma natureza qualitativa e exploratória. O estudo evidenciou que não houve muitas demissões no setor de contabilidade, o que pode estar relacionado ao aumento dos serviços ocasionados por outras demissões que precisaram ser realizadas pelos profissionais de contabilidade, assim como o aumento dos estudos e repasse de informações aos clientes, para adequação às leis e normas implementadas pelo Governo nesse período de pandemia. $O$ estudo demonstrou também que a maioria dos entrevistados não estão organizados, confortáveis, motivados para o trabalho em home office, uma vez que este tipo de trabalho afeta no desempenho das tarefas e a grande maioria dos entrevistados preferem a modalidade presencial.

Palavras chave: Contabilidade, Contadores, Covid-19

\section{INTRODUÇÃO}

Atualmente vivemos uma situação sem nenhum precedente, e o ano de 2020 começou com um grande desafio para os empresários brasileiros, entre eles os escritórios de contabilidade. A crise que vem impactando o mundo inteiro, tanto na saúde quanto na economia, está obrigando os empreendedores a repensarem seus métodos de trabalho. Cada dia que passa, os empresários reavaliam as medidas que podem tomar diante da crise causada pela COVID-19 (MARQUES,2020).

Neste cenário o contador tem um papel fundamental, por isso, agora, mais do que nunca, os contadores devem se informar e estudar sobre todos os cenários e medidas impostas pelo governo (CORREA, 2020), para auxiliar e apresentar todas as medidas aos seus clientes e garantir que adotem as melhores condutas para manter a sustentabilidade dos negócios durante a pandemia do coronavírus. 
A finalidade deste estudo é demonstrar como tem sido as primeiras medidas de enfrentamento dos contadores e contabilistas diante de tal cenário. Este estudo possui uma natureza qualitativa e exploratória, constitui um estudo de caso do tipo descritivo, em que empregou-se como instrumentos de pesquisa, a revisão bibliográfica em periódicos, livros e sites, e entrevista com uso de formulários on-line. Obteve-se quarenta e duas respostas aos formulários enviados para escritórios de contabilidade e contabilistas de CataguasesMG. A pesquisa se deu entre os meses de maio e junho de 2020. Utilizou-se para análise dos dados a técnica de análise de conteúdo.

\section{A CONTABILIDADE, O PROFISSIONAL DE CONTABILIDADE E OS SERVIÇOS}

Segundo Hendriksen e Van Breda (1999), não se sabe quem inventou a contabilidade, o que se sabe é que existem registros de transações financeiras de quatro mil anos atrás, e que foi na Itália em meados do século XIV que surgiu o sistema de escrituração por partidas dobradas que se utiliza atualmente.

O senso-comum geralmente associa a contabilidade a uma ciência exata, entretanto, cientificamente a Contabilidade é enquadrada no campo das ciências sociais aplicadas (IUDÍCIBUS, 2010).

A Contabilidade se adapta as transformações e desenvolvimento da sociedade, ainda de acordo com Hendriksen \& Breda (1999, p.38) a Contabilidade desenvolveu-se em resposta a mudanças no ambiente, novas descobertas e progressos tecnológicos. Não há motivo para crer que a Contabilidade não continue a evoluir em resposta a mudanças que estamos observando em nossos tempos.

O profissional contábil deve sempre buscar as oportunidades de atualização de seus conhecimentos, seja devido ao dinamismo do mercado, seja devido às frequentes modificações efetuadas nas normas contábeis e na legislação (VIELLE, BIANCHI, 2016). A Contabilidade necessita sempre se sintonizar com a evolução social e tecnológica (SANTOS et al., 2008).

Os escritórios contábeis são sociedades civis, constituídas com o objetivo de prestar serviços contábeis para outras organizações industriais, comerciais e outras prestadoras de serviços. A Resolução CFC n. 1.098/07 discrimina duas modalidades de organizações contábeis: escritório individual, caracterizado quando o contabilista, embora sem personificação jurídica, executa suas atividades independentemente do local e do número de empresas ou serviços sob sua responsabilidade; e organização contábil, que se trata de pessoa jurídica de natureza civil, constituída sob a forma de sociedade, tendo por objetivo a prestação de serviços profissionais de contabilidade. (WRUBEL, TOIGO E LAVARDA, 2015)

Thomé (2001) aborda que os serviços prestados são: a escrituração contábil, a conciliação de contas, a elaboração de demonstrações financeiras, as declarações fiscais, a contabilidade gerencial, as obrigações acessórias e eletrônicas, entre outros.

Para cumprir com todos os prazos e todas essas obrigações os escritórios buscam se organizar em rotinas sistemáticas a fim de atender as necessidades dos clientes e as necessidades governamentais. (WRUBEL, TOIGO E LAVARDA, 2015) 


\section{COVID-19 NO BRASIL E NO MUNDO}

A Organização Mundial da Saúde (OMS) declarou, em 30 de janeiro de 2020, que o surto da doença causada pelo novo coronavírus (COVID-19) constitui uma Emergência de Saúde Pública de Importância Internacional - o mais alto nível de alerta da Organização, conforme previsto no Regulamento Sanitário Internacional. Em 11 de março de 2020, a COVID-19 foi caracterizada pela OMS como uma pandemia. (OPAS, 2020).

Os casos de Covid-19 confirmados no mundo, até 31 de maio de 2020 superaram os 6 milhões, conforme estudo levantado pelo monitoramento da universidade americana Johns Hopkins. Os EUA são o país com mais casos: cerca de 1,8 milhões. Em segundo lugar vem o Brasil, com 501.985 casos da doença. A Rússia é o terceiro país com mais infecções, com quase 500 mil casos. (G1, 2020).

A Covid-19 tem se difundido pelo mundo rapidamente e gerado choques econômicos com ritmo e intensidade acima dos observado na crise de 2008 e na grande depressão dos anos de 1930. (JUNIOR, RITA, 2020). Como chama atenção Nouriel Roubini (2020, p. 1) em artigo publicado no Project Syndicate,

[...] nesses dois episódios anteriores, os mercados de ações caíram $50 \%$ ou mais, os mercados de crédito congelaram, as falências em massa seguiram- se, as taxas de desemprego subiram acima de $10 \%$, e o PIB contraiu a uma taxa anualizada de $10 \%$ ou mais. Mas tudo isso levou cerca de três anos para acontecer. Na crise atual, resultados macroeconômicos e financeiros igualmente terríveis se materializaram em três semanas.

O Indicador Antecedente Composto da Economia Brasileira (Iace), calculado pelo Instituto Brasileiro de Economia, da Fundação Getúlio Vargas (FGV/Ibre), em parceria com o The Conference Board (TCB), caiu 10,1\% em abril de 2020, na comparação com março de 2020, passando de 112,6 para 101,2 pontos. (GANDRA, A., 2020).

É a maior queda da série histórica iniciada em 1996, de acordo com a FGV. Em março de 2020, o Iace teve redução de 6,2\% em relação a fevereiro de 2020 (120,1 pontos). Ele já mostra impactos da covid-19 na economia. (GANDRA, A., 2020).

Os autores JUNIOR, RITA (2020, p. 466,467), consideram que:

O efeito simultâneo da crise sobre a demanda e a oferta das economias pode se transformar em uma combinação bastante lesiva para economia, como pode ser observado no Figura 1. Em outras palavras, os reflexos das falências das empresas e do desemprego gerados no setor de serviços contaminarão a demanda por bens produzidos nos setores industrial e agrícola, que passarão a produzir menos aumentando o risco de desabastecimento. A consequência direta de tal dinâmica é o aumento da inadimplência das empresas e famílias causando uma crise financeira e o colapso do sistema de crédito. 
As políticas públicas terão que evitar tanto a paralisia do sistema de saúde, como os efeitos negativos do lockdown sobre as famílias, empresas e bancos. (JUNIOR, RITA, 2020).

Figura 1 - Dinâmica econômica do vírus sem políticas macroeconômicas compensatórias.

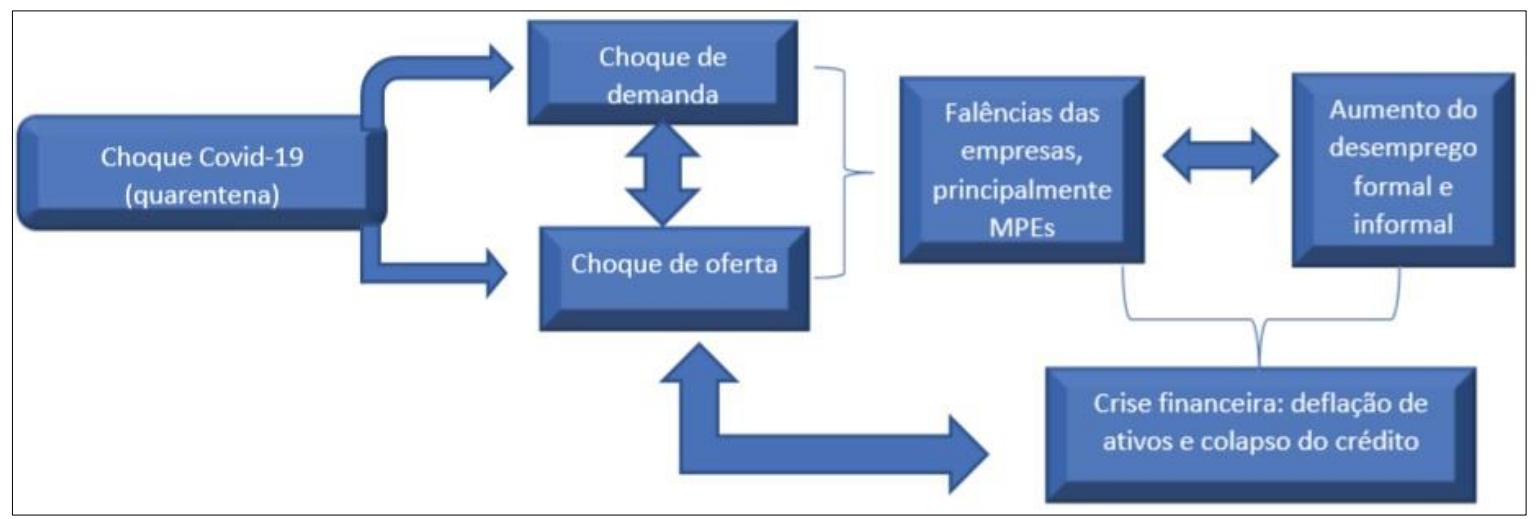

Fonte: (JUNIOR, RITA, 2020).

\section{ESTUDO DE CASO}

Após análise dos dados verificou-se que apenas 21,4\% dos entrevistados alteraram sua modalidade de trabalho, adotando o trabalho em home Office, os demais 78,6\% continuam na modalidade de trabalho presencial em escritórios e empresas.

Aproximadamente $75 \%$ dos entrevistados que disseram estar atuando em home office, afirmam que tem preferência pela modalidade de trabalho presencial.

Quando questionados sobre a estrutura do home office, $44 \%$ dos participantes acreditam que a estrutura que possuem (internet, computador e espaço) são boas, fato que contribui para os resultados do trabalho. Os demais $56 \%$ acreditam que a estrutura que possuem é regular.

Acerca do desempenho do trabalho nessa modalidade $22 \%$ dizem que está impactando nos prazos e na eficácia, enquanto $78 \%$ acreditam que atuar nessa modalidade não interfere na performance de seus resultados.

Verificou-se que a qualidade da estrutura do home Office pode afetar na produtividade do trabalho dos contadores, uma vez que os $22 \%$ que disseram que o trabalho remoto está impactando nos prazos e na eficácia, possuem uma estrutura regular para executarem suas tarefas.

A grande maioria dos entrevistados, aproximadamente 98\%, disseram manter sua rotina de horários, independente de estarem em trabalho home office ou no escritório. Os turnos de trabalho predominantes são manhã e tarde.

Em relação à cobrança da chefia imediata na modalidade de trabalho remoto $44 \%$ responderam que estão sendo mais cobrados e para $56 \%$ as exigências da chefia está normal. Já no trabalho presencial 36\% estão sendo mais cobrados e para $64 \%$ o nível de cobrança se manteve normal.

Averiguou-se a respeito das demissões no setor de contabilidade, para a maioria dos participantes, cerca de $74 \%$, afirmam que não perceberam muitas demissões neste setor. Porém quando questionados sobre demissões em outros setores da economia, aproximadamente $88 \%$ afirmam que houve mais demissões nesse período. 
Procurou-se investigar também sobre as obrigações acessórias e cerca de $90 \%$ dos entrevistados disseram não existir a redução dessas obrigações. Aproximadamente $88 \%$ dos participantes relataram que as medidas tributárias e medidas para manutenção de empregos, implementadas pelo Governo Federal, impactaram no aumento do trabalho dos contadores, devido, principalmente, aos estudos necessários para adequar à nova legislação.

\section{CONSIDERAÇÕES FINAIS}

O presente estudo nos permite inferir sobre a importância dos profissionais de contabilidade, principalmente nesse período de pandemia. Verificou-se que o trabalho ficou mais complexo, devido as atualizações e mudanças de leis, que precisaram ser compreendidas para serem aplicadas não apenas nos processos internos dos escritórios contábeis, mas para serem informadas aos clientes. Nisto, percebe-se que o contador possui um papel importante de consultor dos diversos empreendedores que lhes confiam não apenas seus registros, mas a capacidade de gerar informações para a tomada de decisões, vitais em momentos como o vivenciado com esta pandemia.

Depreende-se a partir das análises, que ao contrário de outros setores, os escritórios contábeis não tiveram aumento nas demissões. Acredita-se que um dos fatos possa ser o aumento dos serviços ocasionados por outras demissões que precisaram ser realizadas pelos profissionais contábeis e pelo aumento dos estudos e repasse de informações aos clientes para adequação às leis e normas implementadas pelo Governo nesse período de pandemia.

Por fim, o estudo demonstrou que a maioria dos entrevistados não estão organizados, confortáveis, motivados para o trabalho em home office, uma vez que este tipo de trabalho afeta no desempenho das tarefas e a grande maioria dos entrevistados preferem a modalidade presencial.

Espera-se que outros trabalhos venham confrontar ou corroborar este estudo, uma vez que se trata de um exame realizado nos primeiros meses da pandemia no Brasil.

\section{REFERÊNCIAS BIBLIOGRÁFICAS}

CORREA, Luiz. O papel do Contador com o Coronavírus. 2020. Disponível em: <https://luizcorreacontador.com.br/o-papel-do-contador-com-o-coronavirus/ >. Acesso em: 27. Jun. 2020.

G1. Mundo registra mais de 6 milhões de casos de Covid-19, aponta universidade. 2020. Disponivel em:

$<$ https://g1.globo.com/bemestar/coronavirus/noticia/2020/05/31/mundo-registramais-de-6-milhoes-de-casos-de-covid-19-aponta-universidade.ghtml>. Acesso em:

31.mai.2020.

GANDRA, Alana. Indicador aponta impactos da covid-19 na economia brasileira. 2020. Disponível em: <https://agenciabrasil.ebc.com.br/economia/noticia/202005/indicador-aponta-impactos-da-covid-19-na-economia-brasileira >. Acesso em: 06. Jun. 2020.

GIL, A.C. Métodos e técnicas de pesquisa social. São Paulo: Atlas, 1999. 
HENDRIKSEN, Eldon S.; BREDA, Michael F. Van. Teoria da Contabilidade. 5.ed. São Paulo: Atlas, 1999.

IUDÍCIBUS, S. (Coord.). Contabilidade introdutória. 11.ed. São Paulo: Atlas, 2010

JUNIOR, R. R. F; RITA. L. P. S. Impactos da Covid-19 na Economia: limites, desafios e políticas. 2020. Disponível em: <https://cienciasmedicasbiologicas.ufba.br/index.php/nit/article/view/36183/20968>. Acesso em: 06. Jun. 2020.

MARQUES, Mano. 7 dicas para o contador ajudar o cliente. 2020. Disponível em: $<$ https://blog.fortestecnologia.com.br/dicas-para-contador-ajudar-o-cliente/>. Acesso em: 27. Jun. 2020.

OPAS - Organização Pan-Americana da Saúde. Folha informativa - COVID-19 (doença causada pelo novo coronavírus). 2020. Disponivel em: $<$ https://www.paho.org/bra/index.php?option=com_content $\& v i e w=\operatorname{article} \& i d=6101: \mathrm{co}$ vid19\&Itemid=875> . Acesso em: 31.mai.2020.

ROUBINI, Nouriel. A Greater Depression?. Project Syndicate, [S.1.], p. 1-5, 24 mar. 2020. Disponível em: <https://www.project-syndicate.org/commentary/coronavirusgreater-great-depression-by-nouriel-roubini-2020-03>. Acesso em: 06. Jun. 2020.

SANTOS, J. L. et al.. A importância do capital intelectual na sociedade do conhecimento. ConTexto, Porto Alegre, v. 8, n. 14, p. 1-16, 2º semestre 2008.

THOMÉ, I. Empresas de serviços contábeis: estrutura e funcionamento. São Paulo: Atlas, 2001.

VIELle, A. P. L.; BIANCHI, M. Profissão Contábil em Guias de Cursos de Graduação: Perfil Do Contador, Rotinas Profissionais e Mercado de Trabalho. 2016. Disponível em: $<$ http://local.cnecsan.edu.br/revista/index.php/rac/article/view/379 $>$. Acesso em: 27.mai.2020.

WRUBEL. F.; TOIGO. L.A.; LAVARDA. C.E.F.Mudanças Nas Rotinas Contábeis: Contradições Institucionais E Práxis Humanas. 2015. Disponível em: $<$ https://www.researchgate.net/publication/283563108_MUDANCAS_NAS_ROTI NAS_CONTABEIS_CONTRADICOES_INSTITUCIONAIS_E_PRAXIS_HUMANA $\underline{\text { S}}>$. Acesso em: 27.mai.2020. 


\title{
CONTABILIDADE ECOLÓGICA E AUDITORIA AMBIENTAL
}

\section{RESUMO}

\author{
Daniele de Almeida Oliveira \\ Maria Eduarda Gomes de Souza \\ Maria Eduarda Santos Souza \\ Altamiro Lacerda de Almeida Junior \\ Jesusimar de Oliveira Dornelas
}

As empresas estão sendo forçadas a adotarem mecanismos de proteção ao meio ambiente. Deste modo, estão sendo implantados nas empresas os Sistemas de Gestão Ambiental e para que seja feito o controle desse gerenciamento, a Contabilidade é tida como uma das melhores ferramentas para ser usada nesse processo. Sendo assim, o objetivo principal desse trabalho é identificar a responsabilidade das empresas em relação ao meio ambiente, o papel do contador no contexto ambiental e como ele consegue minimizar os problemas ecológicos causados pelas empresas. Identificamos também a importância da auditoria ambiental como instrumento gerencial para análise de desempenho e sustentabilidade ambiental da empresa.

Palavras-chave: Contabilidade Ecológica. Auditoria Ambiental. Gestão Ambiental.

\section{INTRODUÇÃO}

As pressões pela melhoria da qualidade ambiental nas empresas iniciaram pelos ecólogos e com o tempo se espalhou aos acordos, regulamentações de comércio, sociedade, entre outros. Com isso, as empresas se viram na responsabilidade de realizar a produção de forma que não houvesse agressão a natureza, pois de certa forma, para que as empresas se mantenham em operação, elas precisam ser aceitas onde estão inseridas, necessitam estar de acordo com as regulamentações, precisam de fornecedores e clientes.

As empresas entenderam ser necessário incluir em seu planejamento estratégico a sustentabilidade, uma vez que o futuro e a continuidade da sociedade e de seus próprios negócios estão diretamente ligados. As empresas que constroem um desenvolvimento sustentável conseguem satisfazer as necessidades da sociedade sem comprometer que gerações futuras também satisfaçam essas necessidades. Sendo assim, para que as organizações conseguissem atingir esse objetivo, é necessário a implantação da gestão ambiental, essa gestão, tem por objetivo planejar, avaliar e controlar o impacto de sua produção no ambiente.

Essa implementação trouxe um impacto negativamente significativo no fluxo de caixa das empresas e, consequentemente, na lucratividade, sendo esse, o principal motivo para que a haja resistência dos empresários em investirem na proteção do meio ambiente.

Este artigo, trata sobre aspectos referentes a contabilidade e a auditoria no ambiente ecológico. Utilizou-se nesse estudo a pesquisa bibliográfica fundamentada em alguns autores como o exemplo de Carvalho (2008), Donaire (1999), Bergamini Junior (1999) entre outros, que mostram com clareza como a contabilidade contribui nas questões ambientais.

\section{CONTABILIDADE ECOLÓGICA}

A Contabilidade é considerada um sistema de informações que tem o objetivo de auxiliar o gerenciamento da empresa. Para Marion e Iudícibus (2000): "O objetivo da 